\title{
Thiazolidine Deprotection by 2-Aminobenzamide-based Aldehyde Scavenger for One-pot Multiple Peptide Ligation
}

\author{
[a] K. Nakatsu, Prof. Dr. H. Murakami, Dr. G. Hayashi \\ Department of Biomolecular Engineering \\ Graduate School of Engineering, Nagoya University \\ Furo-cho, Chikusa-ku, Nagoya 464-8603, Japan \\ E-mail: hayashi@chembio.nagoya-u.ac.jp \\ [b] Prof. Dr. H. Murakami \\ Institute of Nano-Life-Systems \\ Institutes of Innovation for Future Society, Nagoya University \\ Furo-cho, Chikusa-ku, Nagoya 464-8603, Japan \\ [c] Prof. Dr. A. Okamoto \\ Department of Chemistry and Biotechnology \\ Graduate School of Engineering, The University of Tokyo \\ 7-3-1 Hongo, Bunkyo-ku, Tokyo 113-8656, Japan \\ E-mail: okamoto@chembio.t.u-tokyo.ac.jp \\ [d] Prof. Dr. A. Okamoto \\ Research Center for Advanced Science and Technology \\ The University of Tokyo \\ 4-6-1 Komaba, Meguro-ku, Tokyo 153-8904, Japan
}

Koki Nakatsu,${ }^{[a]}$ Hiroshi Murakami ${ }^{[a, b]}$ Gosuke Hayashi, ${ }^{*[a]}$ Akimitsu Okamoto ${ }^{*[, d]}$

\begin{abstract}
Strategies for one-pot peptide ligation enable chemists to access synthetic proteins at a high yield in a short time. Herein, we report a new one-pot multi-segments ligation strategy using $\mathrm{N}$-terminal thiazolidine (Thz) peptide and a formaldehyde scavenger. Among our designed 2aminobenzamide-based aldehyde scavengers, 2-amino-5-methoxy- $N$ ', $N$ '-dimethylbenzohydrazide showed a good ability to capture formaldehyde from Thz at pH 4.0. This scavenger had compatibility with the conditions of native chemical ligation at $\mathrm{pH} 7.5$. Using this scavenger for a model peptide ligation system, we performed one-pot four-segment ligation at a high yield without significant side reactions.
\end{abstract}

\section{Introduction}

Chemical protein synthesis ${ }^{[1-3]}$ is a promising methodology for preparing site-specifically engineered proteins with unnatural amino acids, which are hard to be accessed with genetically engineering methods. Typically, in chemical protein synthesis, peptide segments prepared by solid-phase peptide synthesis (SPPS) ${ }^{[4]}$ are condensed via peptide ligation reactions. ${ }^{[5-8]}$ From the invention of native chemical ligation (NCL), ${ }^{[5,9,10]}$ in which unprotected peptide segments ligated between $\mathrm{N}$-terminal cysteine (Cys) and C-terminal thioester, the field of chemical protein synthesis has been expanding rapidly. To achieve an efficient synthesis of a variety of useful and/or synthetically challenging proteins, peptide and protein chemists have been seeking to develop more sophisticated chemical tools. ${ }^{[11,12]}$ As one of such attempts, many types of one-pot peptide ligation strategies have been reported in this field to avoid laborious and time-consuming purification/lyophilization steps after ligation reaction. ${ }^{[13]}$ One-pot ligation tends to give a higher yield than that of conventional methods because there is no need to isolate ligation intermediates. Among various one-pot peptide ligation strategies, ${ }^{[14-23]}$ the use of protecting groups at $\mathrm{N}$-terminal amine or thiol of Cys at internal segments was the simplest approach and reported in many research groups. For example, acetamidomethyl (Acm) group $^{[22]}$ and trifluoroacetamidomethyl (Tfacm) for thiol group, ${ }^{[24]}$ 4-(dimethylamino)phenacyloxycarbonyl (Mapoc), ${ }^{[25]} p$ borobenzyloxycarbonyl group (Dobz), ${ }^{[19]}$ allyloxycarbonyl (Alloc) ${ }^{[26-28]}$ and 9-fluorenylmethyloxycarboyl (Fmoc) for amine group ${ }^{[29]}$ were successful $\mathrm{N}$-terminal cysteinyl protecting groups in one-pot peptide ligation.

As an equivalent of a protected Cys moiety, 1,3-thiazolidine-4-carbonyl (Thz) group is employed in many reports of chemical protein synthesis probably because Thz is easy to be introduced to the $\mathrm{N}$-terminus of a peptide with a commercially available amino acid monomer (Boc-Thz-OH) and does not affect the charge and solubility of peptide segments. As pioneering research, Bang and Kent demonstrated that the Thz group could be applied for one-pot three segments ligation using methoxyamine as a decaging reagent at acidic conditions (Scheme 1a.). ${ }^{[30]}$ However, in the second ligation after Thz ring-opening, methoxyamine can also react with thioester moiety of the $\mathrm{N}$-terminal segment because of the high nucleophilicity of the amino group of methoxyamine. Thus, in this method, an excess amount of the third $\mathrm{N}$-terminal segment needs to be added to reach a full conversion in three peptide segments ligation. Palladium or copper-mediated Thz ring-opening was reported by the Brik group ${ }^{[31-33]}$ and by the Otaka group ${ }^{[34]}$ respectively (Scheme $1 \mathrm{~b}$.). These metals can promote the hydrolysis of Thz as a Lewis acid to the sulfur atom to produce Cys and formaldehyde. Although this metal-mediated mechanism enabled fast deprotection of Thz, there is space to improve the conditions for one-pot peptide ligation of more than three segments. Katayama and Morisue reported Thz ring-opening reaction using 2,2'-dipyridyl disulfide (DPDS) in an acidic solution. ${ }^{[35]}$ However, this approach could not be applied to one-pot peptide ligation because the reductive condition used in NCL would easily reduce the disulfide bond.

Herein, we report a one-pot repetitive Thz deprotection without thioester degradation using a new 2-aminobenzamide-based deprotection reagent. Because the reaction of Thz deprotection in aqueous conditions involves formaldehyde formation, we hypothesized 
that Thz could efficiently be deprotected by using a reliable scavenger for formaldehyde. We focused on 2-aminobenzamide-based molecules, which are reactive with aldehyde and produce hydrolytically stable products. We found that 2-amino-5-methoxy-N',N'dimethylbenzohydrazide (AMDBH) could open Thz ring by capturing formaldehyde released from Thz in acidic conditions ( $\mathrm{pH} \sim 4$ ) (Scheme 1c.). In contrast to methoxyamine, due to the lower nucleophilicity of 2-aminobenzamide derivatives, AMDBH had much smaller effects on thioester moiety in $\mathrm{NCL}$ conditions $(\mathrm{pH} \sim 7)$ than methoxyamine. By adding this compound to the $\mathrm{NCL}$ buffer and simply controlling $\mathrm{pH}$, we accomplished an efficient one-pot multi-segments ligation without a significant side reaction.

(a) Previous work (1)

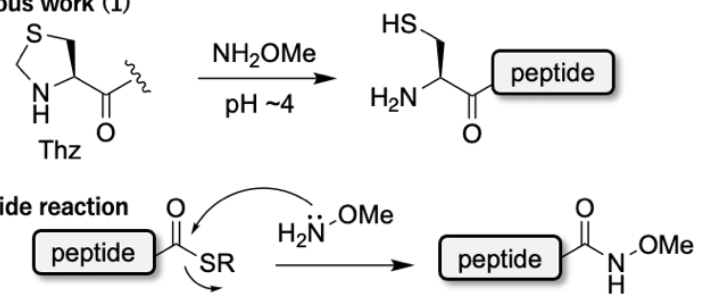

(b) Previous work (2)

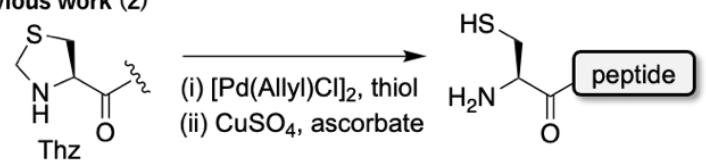

(c) This work

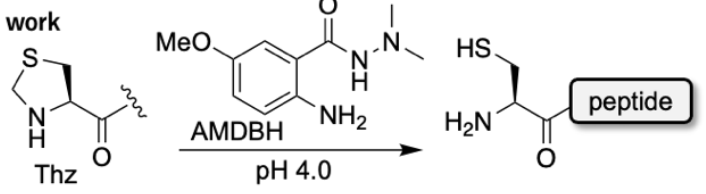

Scheme 1. N-terminal thiazolidine (Thz) as a precursor of cysteine. (a) Methoxyamine-mediated Thz ring-opening and its side reaction. (b) Pd or Cu mediated Thz ringopening. (c) This work: an aldehyde scavenger mediated Thz ring-opening for one-pot multiple peptide ligation.

\section{Results and Discussion}

\section{Design and synthesis of aldehyde scavengers}

We began this study with the design and preparation of 2-aminobenzamide-based aldehyde scavengers. In the previous report, ${ }^{[36]}$ Kitov et al. demonstrated that aniline derivatives containing nucleophile at ortho position of amine could react with aldehyde and 2-amino benzamidoxime (ABAO) had a high reactivity especially at $\mathrm{pH}$ 4.0-4.5 and p-methoxy ABAO (PMA) indicated enhanced reactivity to aldehyde (Scheme S1.). Because Thz has an acid-liable thioaminal component ${ }^{[37,38]}$ and such aniline derivatives can capture formaldehyde released from Thz, we hypothesized that these aniline derivatives could decage an N-terminal Thz group at lower $\mathrm{pH}$. To achieve one-pot peptide ligation by repetitive Thz deprotection, the aldehyde scavenger is demanded not only to efficiently trap formaldehyde only at lower $\mathrm{pH}(\mathrm{pH}$ $\sim 4$ ) and but also to have a negligible effect on thioester moiety under a wide range of $\mathrm{pH}(\mathrm{pH}$ 4-7). Because ABAO and PMA have a highly nucleophilic amidoxime moiety, which could attack thioester ${ }^{[39]}$ we newly designed four types of 2-aminobenzamide derived scavengers (s1, s2, s3, s4, Figure 1a.). As nucleophiles at ortho position of amine, we chose O-methylhydroxamic acid (s1, s3) and N',N'-dimethylhydrazide (s2, s4), which have a terminal nitrogen atom with higher nucleophilicity than that of amide due to a-effect. ${ }^{[40,41]}$ Methyl groups attached on the terminal heteroatoms ( $\mathrm{O}$ or $\mathrm{N}$ ) were introduced to suppress the total nucleophilicity of scavengers. As with the case of ABAO and PMA, a methoxy group was introduced to the para position of the amine group to improve the ability to trap aldehydes (s3, s4). ${ }^{[36,42]}$ These four types of 2-aminobenzamide derivatives were synthesized via a single-step reaction of a nucleophilic attack of methoxyamine or $\mathrm{N}, \mathrm{N}$ dimethylhydrazine to commercially available isatoic anhydride derivatives (see the chapter of organic synthesis at experimental section.).

\section{Thz ring-opening using formaldehyde scavengers}

To conduct Thz ring-opening test, we synthesized an N-terminal Thz model peptide 1 (H-Thz-LYRVTKLYRVG-NH$)$ via standard FmocSPPS (Figure S1a). First, peptide 1 was dissolved to $6 \mathrm{M} \mathrm{Gn} \cdot \mathrm{HCl}, 0.2 \mathrm{M}$ phosphate buffer containing $200 \mathrm{mM}$ scavengers and standard NCL additives (100 mM 4-mercaptophenylacetic acid (MPAA) and $20 \mathrm{mM}$ tris(2-carboxyethyl)phosphine $\bullet$ hydrochloride $(\mathrm{TCEP} \cdot \mathrm{HCl}))$ and the reaction mixture was stirred at $37^{\circ} \mathrm{C}$ (this condition will be called as 'condition A') (Figure 1b). From the analysis of RP-HPLC and MALDITOF/MS, Thz ring-opening proceeded with all tested 2-aminobenzamide-based scavengers at $\mathrm{pH} 4.5$ and $\mathrm{N}$-terminal Cys peptide 1' was observed (Figure 1d and S2). As a general trend, scavengers with a 5-methoxy group (s3, s4) were much more reactive than those with no modification (s1, s2). Scavengers with N',N'-dimethylhydrazide (s2, s4) were slightly reactive than those with O-methylhydroxamic acid (s1, s3). AMDBH (s4) had the highest reactivity in the Thz ring-opening and the conversion yield reached $98 \%$ in $6 \mathrm{~h}$. Using AMDBH (s4), we conducted the same reaction with different acidic $\mathrm{pHs}(3.5,4.0,5.0)$ at condition A (Figure 1e and S3). We found that the optimum pH for Thz ring-opening was around 4.0 and the reaction went to completion in $5 \mathrm{~h}$ (Figure 1f). We also conducted this experiment at $\mathrm{pH} 4.0,50^{\circ} \mathrm{C}$. The reaction was accelerated and the deprotection of Thz was completed within $2 \mathrm{~h}$ (Figure S4). As the deprotection of Thz proceeded, a 
non-peptide peak probably derived from formaldehyde-trapped AMDBH (t4) was observed in the HPLC analysis. To simplify the reaction, we also conducted a reaction between AMDBH $(20 \mathrm{mM})$ and formaldehyde $(30 \mathrm{mM})$ in the $\mathrm{NaOAc}$ buffer $(\mathrm{pH} 4.5)$ at room temperature (Figure 1c and S5) and performed HPLC analysis using the same gradient as the Thz stability test. Within 10 min, we observed the conversion of s4 into t4. Because ESI MS analysis indicated that the mass of t4's peak is 12 Da higher than that of s4, we concluded that $\mathbf{t} 4$ is the desired aminal product after scavenging formaldehyde.

Then, we tested the stability of a Thz group at NCL conditions ( $\mathrm{pH} 7.0$ and 7.5) with AMDBH (s4) at condition A. While Thz degraded gradually at all tested pHs, at 7.5 in $12 \mathrm{~h}$, the remaining yield of Thz peptide 1 was $94 \%$ (Figure 1e, 1g, and S6); Thz was stable enough when conducting $\mathrm{NCL}$ at $\mathrm{pH}$ 7.5. From these results, AMDBH (s4) worked efficiently at lower $\mathrm{pH}$ and has the potential to be used for Thz ring-opening after $\mathrm{NCL}$ in a one-pot manner by switching $\mathrm{pH}$ from 7.5 to 4.0 .

We also checked the dependence of AMDBH's concentration on the ring-opening reaction. When reducing the AMDBH concentration to $50 \mathrm{mM}$ or $100 \mathrm{mM}$, the Thz ring-opening slowed down at pH 4.5 and pH 7.0 (Figure S7 and S8). From this result, AMDBH should be added at a high concentration for a fast reaction rate. To confirm the role of NCL additives (MPAA, TCEP) in the Thz ring-opening reaction, we conducted the same experiment without these additives. The conversion was almost the same as the conditions with NCL additives both at $\mathrm{pH} 4.5$ and at $\mathrm{pH} 7.0$ (Figure S9), indicating that MPAA and TCEP were not relevant to the reaction mechanism.

(a)<smiles>COc1ccc(N)c(C(=O)NN(C)C)c1</smiles>

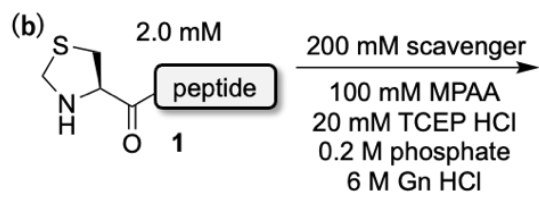

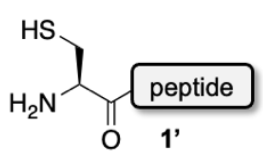

(c)<smiles>[R1]NC(=O)c1cc([R])ccc1N</smiles>
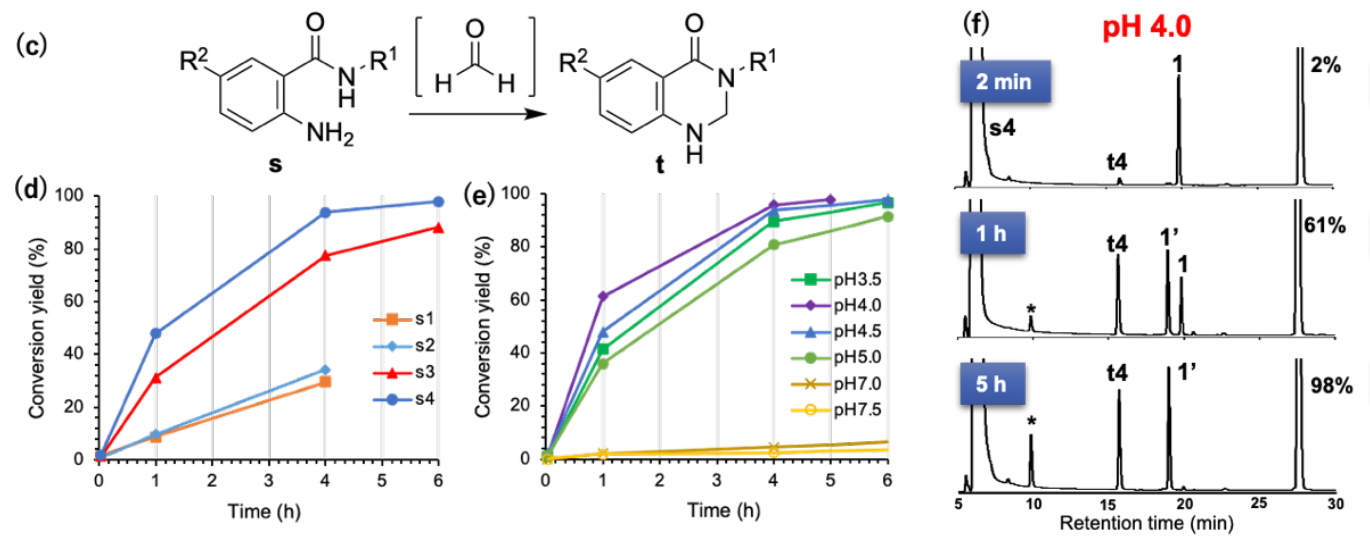

(g)

pH 7.5

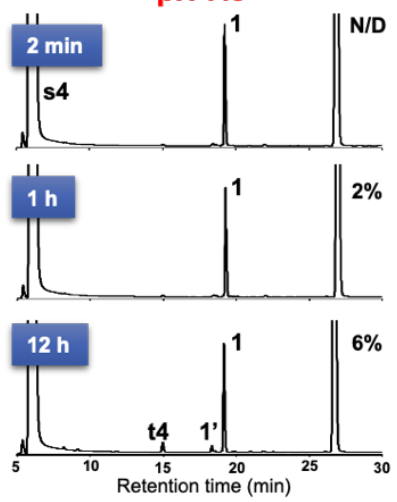

Figure 1. N-terminal Thz ring-opening using 2-aminobenzamide-based aldehyde scavengers. HPLC gradient: acetonitrile $10-40 \%$ for 30 min. (a) Aldehyde scavengers in this work. (b) Reaction scheme of Thz ring-opening test. (c) The reaction between an aldehyde scavenger and formaldehyde from Thz. (d) Timecourse analysis of Thz ring-opening with s1-s4 at pH4.5. Conversion yields were calculated from the peak area of HPLC analysis at $220 \mathrm{~nm}$. (e) Time-course analysis of Thz ring-opening with $\mathbf{s} 4$ at deferent pHs. (f) HPLC analysis of Thz ring-opening with $\mathbf{s} 4$ at pH 4.0. * is a non-peptide peak. (g) HPLC analysis of Thz stability test with $\mathbf{s} 4$ at $\mathrm{pH} 7.5$.

\section{Compatibility of aldehyde scavengers to a thioester moiety at NCL conditions}

Methoxyamine could react with thioester at NCL conditions because thioester moieties are susceptible to nucleophilic attacks. ${ }^{\text {[30] }}$ We tested the compatibility of AMDBH with thioester moieties. Glycyl thioester peptide 2 (H-SYRKG-diketopiperazine (DKP) thioester) was synthesized using an Fmoc-compatible peptide thioesterification method based on Cysteinyl Prolyl Imide (CPI), which we reported previously (Figure S10.). ${ }^{[33,44]}$ The peptide 2 was exposed to $200 \mathrm{mM}$ methoxyamine or AMDBH buffer based on 'condition A' at pH 7.0 or 7.5 and the reaction was monitored by RP-HPLC and MALDI-TOF/MS (Figure 2a.). In the case of methoxyamine, the thioester peptide was quantitatively converted into C-terminal methoxyamine adduct 2-MA within $1 \mathrm{~h}$ both at pH 7.0 and at 7.5 (Figure $2 \mathrm{~b}$ and $\mathrm{S} 11 \mathrm{~b})$. On the other hand, in the case of $\mathrm{AMDBH}$, the MPAA thioester peptide 2-MP remained as the main peak in $1 \mathrm{~h}$ and ADMBH adduct 2-AD and hydrolyzed peptide 2-hy were observed at almost the same ratio (Figure $3 \mathrm{c}$ and S11c). From these results, AMDBH has much smaller effects on thioester moiety in NCL conditions than methoxyamine does. 
(a)
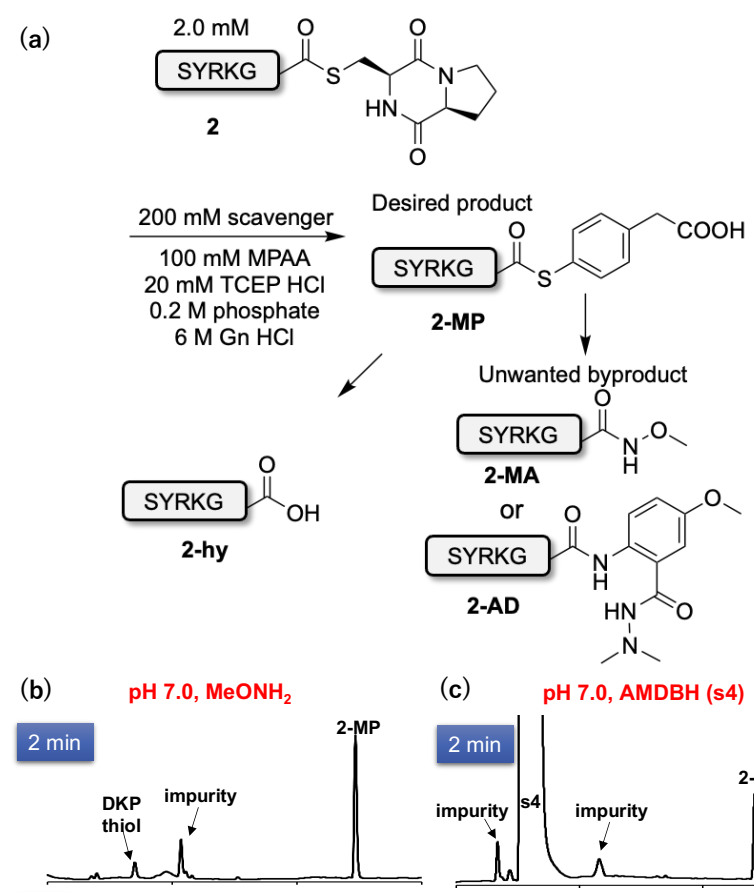

(c) $\quad \mathrm{pH} 7.0$, AMDBH (s4)
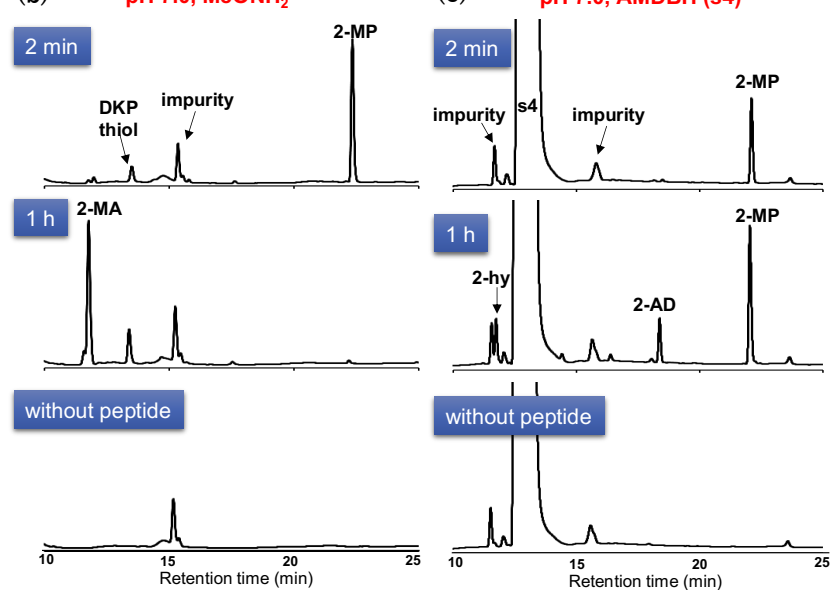

Figure 2. C-terminal DKP thioester stability test with aldehyde scavengers. HPLC gradient: acetonitrile 1-25\% for 25 min. (a) A Reaction scheme of DKP thioester stability test in NCL buffer. (b) HPLC analysis with $200 \mathrm{mM}$ methoxyamine at pH 7.0. (c) HPLC analysis with $200 \mathrm{mM} \mathrm{AMDBH}$ (s4) at pH 7.0. To discriminate the non-peptidyl peaks, the buffers without peptides were analyzed by HPLC at the same gradient.

\section{One-pot multiple peptide ligation with model peptides}

Encouraged by these positive results, we tried to conduct one-pot peptide ligation with the combination of AMDBH and $\mathrm{N}$-terminal Thz using model peptides. We synthesized four model peptide segments $(\mathbf{3}, \mathbf{4}, \mathbf{5}, \mathbf{6})$ as shown in Figure 3 a. To introduce thioester moieties to the $\mathrm{C}$-terminus of peptides, we used the thioesterification method based on CPI. This one-pot ligation was carried out in the buffer containing $6 \mathrm{M} \mathrm{Gn} \cdot \mathrm{HCl}, 0.1 \mathrm{M}$ phosphate, $100 \mathrm{mM}$ MPAA, $20 \mathrm{mM}$ TCEP. The concentration of phosphate was reduced from 'condition A' to ease the adjustment of $\mathrm{pH}$ from 7.5 to 4.0. This experiment was monitored by RP-HPLC and MALDI-TOF/MS.

The first NCL between 5 and 6 went to completion at pH 7.5 within $2 \mathrm{~h}$ and ligated peptide 7 emerged (Figure 3b). Then, the ligation buffer was acidified to $\mathrm{pH} \sim 4.0$ with $12 \mathrm{M} \mathrm{HCl}$ aq. to convert $\mathrm{N}$-terminal Thz into Cys. To shorten the reaction time, the acidified mixture was stirred at $50^{\circ} \mathrm{C}$ at this trial. The conversion of 7 to Cys peptide 7 ' proceeded within $4 \mathrm{~h}$ (Figure 3c). After readjustment of $\mathrm{pH}$ to $\sim 7.5$ by $12 \mathrm{M} \mathrm{NaOH}$ aq., peptide 3 was added to the mixture and the second NCL was proceeded cleanly within $3 \mathrm{~h}$, and ligated peptide 8 was produced (Figure $3 \mathrm{~d}$ ). Thz ring-opening was conducted again at $50{ }^{\circ} \mathrm{C}, \mathrm{pH} \sim 4.0$ and 8 converted to Cys peptide 8 ' within $3 \mathrm{~h}$ (Figure 3e). The third NCL between $\mathbf{8}^{\prime}$ and $\mathbf{2}$ was performed at $\mathrm{pH} \sim 7.0$ and the final ligated peptide 9 was observed as the main product in the HPLC analysis of the reaction mixture after $1 \mathrm{~h}$ stirring (Figure $3 \mathrm{f}$ ). Through the one-pot reaction, AMDBH-adducts were not observed as an obvious peak at the HPLC chart. The ligation mixture was purified by a preparative RP-HPLC and 9 was isolated in $42 \%$ yield calculated from the amount of 6 (Figure $3 g$ and $3 f$ ). 
(a)

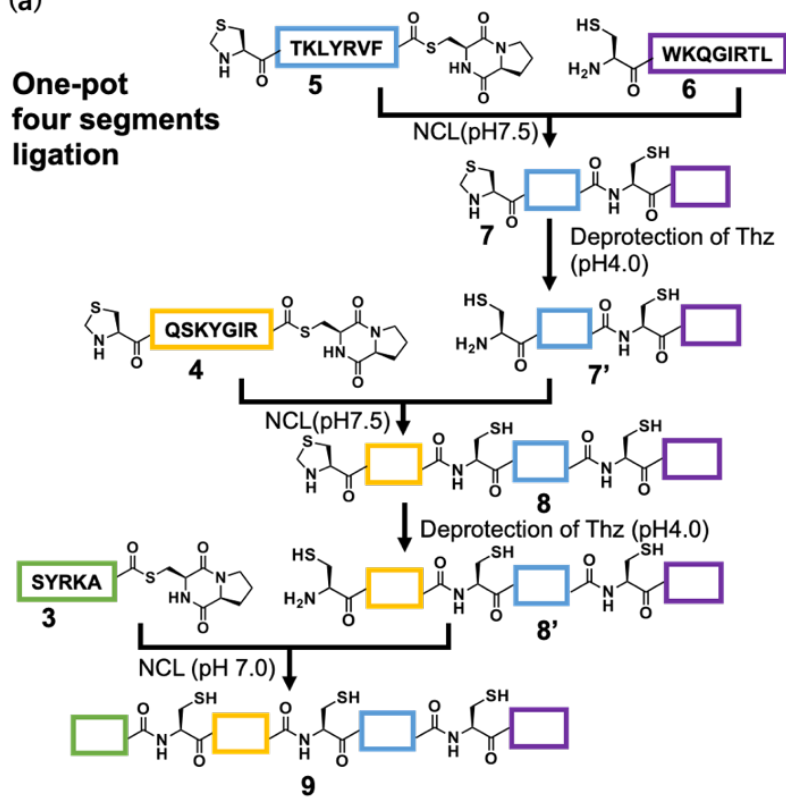

(b) 1 (s)

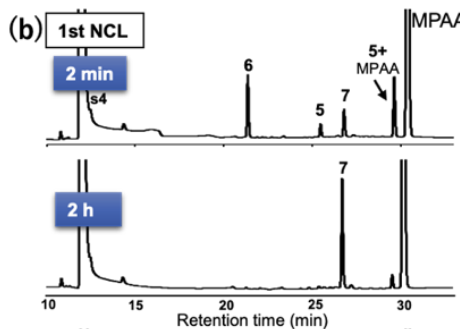

(c) 1st Thz decaging

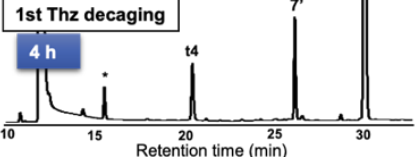

(d)

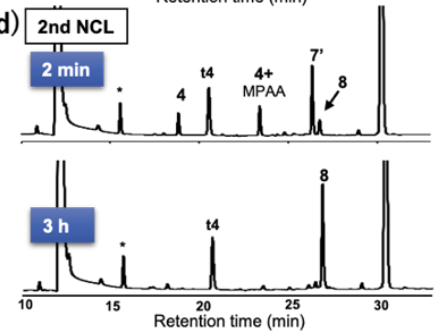

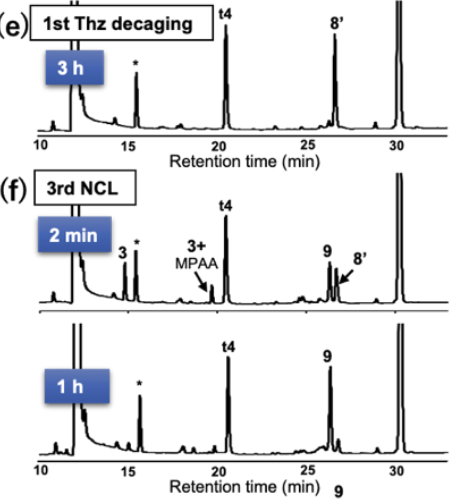

(g)

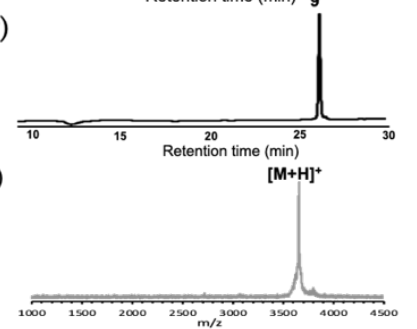

Figure 3. One-pot four-segment ligation using model peptides. HPLC gradient: acetonitrile $1-40 \%$ for 30 min. (a) The reaction scheme and sequences of model peptides. (b) HPLC analysis of 1st NCL. * is a non-peptide peak. (c) HPLC analysis of the first deprotection of Thz. (d) HPLC analysis of the second NCL. (e) HPLC analysis of the second deprotection of Thz. (f) HPLC analysis of the third NCL. (g) HPLC profile of 9 after HPLC purification. (f) MALDI-TOF/MS spectrum of purified 9. The observed mass was $3656.2 \mathrm{Da}\left(\right.$ calcd $\left.3657.4 \mathrm{Da},[\mathrm{M}+\mathrm{H}]^{+}\right)$.

\section{Conclusion}

In summary, we developed a novel one-pot four-segment ligation strategy by developing a 2-aminobenzamide-based aldehyde scavenger for $\mathrm{N}$-terminal Thz deprotection. This scavenger could efficiently open the Thz ring by capturing formaldehyde only at $\mathrm{pH} \sim 4.0$ and had a negligible effect on thioester moieties of peptides in the NCL condition at $\mathrm{pH} \sim 7.5$. We accomplished one-pot four-segment ligation in the NCL buffer containing AMDBH by adjusting pH between 7.5 and 4.0 repeatedly. The simple protocol offered a good yield of ligation product. While the use of basic $\mathrm{pH}$ for removal of protecting groups sometimes cause side-chain degradation or epimerization, an acidic condition used in this study does not need to be concerned about such side reactions, suggesting that our strategy could be employed for the assembly of more than four segments by repeating the $\mathrm{pH}$ control. We believe that this method reported here will contribute to the efficient one-pot synthesis of challenging protein targets such as large proteins or brunched proteins. Furthermore, we think that these 2-aminobenzamide derivatives have the potential to be used in other applications. For example, because these derivatives can react with aldehydes in aqueous conditions without significant degradation of nucleophile-liable moieties, these derivatives could also be used for selective reactions with aldehydes in cells or tissues, in which thioester moieties are prevalent.

\section{Acknowledgements}

This work was supported by the Japan Society for the Promotion of Science (JSPS) KAKENHI 18H03931, 18H05504, and 19 K22245 (A. O.), 18K05313, 19H05287, and 20H04704, JST PRESTO JPMJPR19K6 (G. H.) and AMED under Grant Numbers $20 \mathrm{he} 0622010 \mathrm{~h} 0001$ (H. M.). This work was conducted both at Nagoya University and at the University of Tokyo.

Keywords: chemical protein synthesis $\bullet$ native chemical ligation $\bullet$ thiazolidine $\bullet$ peptides $\bullet$ protecting groups

[1] S. B. H. Kent, Protein Sci. 2019, 28, 313-328

[2] Y. Tan, H. Wu, T. Wei, X. Li, J. Am. Chem. Soc. 2020, 142, 20288-20298.

[3] V. Agouridas, O. El Mahdi, O. Melnyk, J. Med. Chem. 2020, 63, 15140-15152.

[4] R. B. Merrifield, J. Am. Chem. Soc. 1963, 85, 2149-2154. 
[5] P. E. Dawson, T. W. Muir, I. Clark-Lewis, S. B. Kent, Science 1994, 266, 776-779.

[6] V. R. Pattabiraman, A. O. Ogunkoya, J. W. Bode, Angew. Chem. Int. Ed. 2012, 51, 5114-5118.

[7] Y. Zhang, C. Xu, H. Y. Lam, C. L. Lee, X. Li, Proc. Natl. Acad. Sci. U. S. A. 2013, 110, 6657-6662.

[8] N. J. Mitchell, L. R. Malins, X. Liu, R. E. Thompson, B. Chan, L. Radom, R. J. Payne, J. Am. Chem. Soc. 2015, 137, 14011-14014.

[9] A. C. Conibear, E. E. Watson, R. J. Payne, C. F. W. Becker, Chem. Soc. Rev. 2018, 47, 9046-9068.

[10] V. Agouridas, O. El Mahdi, V. Diemer, M. Cargoët, J.-C. M. Monbaliu, O. Melnyk, Chem. Rev. 2019, 119, 7328-7443.

[11] S. Bondalapati, M. Jbara, A. Brik, Nat. Chem. 2016, 8, 407-418.

[12] K. Nakatsu, G. Hayashi, A. Okamoto, Curr. Opin. Chem. Biol. 2020, 58, 10-19.

[13] C. Zuo, B. Zhang, B. Yan, J.-S. Zheng, Org. Biomol. Chem. 2019, 17, 727-744.

[14] D. Bang, B. L. Pentelute, S. B. H. Kent, Angew. Chem. Int. Ed. 2006, 45, 3985-3988.

[15] L. Raibaut, M. Cargoët, N. Ollivier, Y. M. Chang, H. Drobecq, E. Boll, R. Desmet, J.-C. M. Monbaliu, O. Melnyk, Chem. Sci. 2016, 7, $2657-2665$.

[16] Y. Asahina, T. Kawakami, H. Hojo, Chem. Commun. 2017, 53, 2114-2117.

[17] J. Palà-Pujadas, F. Albericio, J. B. Blanco-Canosa, Angew. Chem. Int. Ed. 2018, 57, 16120-16125.

[18] Y. Asahina, T. Kawakami, H. Hojo, European J. Org. Chem. 2019, 2019, 1915-1920.

[19] J. Li, Y. Li, Q. He, Y. Li, H. Li, L. Liu, Org. Biomol. Chem. 2014, 12, 5435-5441.

[20] M. Pan, Y. He, M. Wen, F. Wu, D. Sun, S. Li, L. Zhang, Y. Li, C. Tian, Chem. Commun. 2014, 50, 5837-5839.

[21] K. Aihara, K. Yamaoka, N. Naruse, T. Inokuma, A. Shigenaga, A. Otaka, Org. Lett. 2016, 18, 596-599.

[22] S. K. Maity, M. Jbara, S. Laps, A. Brik, Angew. Chem. Int. Ed. 2016, 55, 8108-8112.

[23] D. T. Flood, J. C. J. Hintzen, M. J. Bird, P. A. Cistrone, J. S. Chen, P. E. Dawson, Angew. Chem. Int. Ed. 2018, 57, 11634-11639.

[24] S. Tang, Y.-Y. Si, Z.-P. Wang, K.-R. Mei, X. Chen, J.-Y. Cheng, J.-S. Zheng, L. Liu, Angew. Chem. Int. Ed. $2015,54,5713-5717$.

[25] S. Ueda, M. Fujita, H. Tamamura, N. Fujii, A. Otaka, Chembiochem 2005, 6, 1983-1986.

[26] N. Kamo, G. Hayashi, A. Okamoto, Angew. Chem. Int. Ed. 2018, 57, 16533-16537.

[27] N. Kamo, G. Hayashi, A. Okamoto, Org. Lett. 2019, 21, 8378-8382.

[28] N. Kamo, T. Kujirai, H. Kurumizaka, H. Murakami, G. Hayashi, A. Okamoto, Chem. Sci. 2021, 12, 5926-5937.

[29] A. Kar, J. Mannuthodikayil, S. Singh, A. Biswas, P. Dubey, A. Das, K. Mandal, Angew. Chem. Int. Ed. 2020, 59, $14796-14801$.

[30] D. Bang, S. B. H. Kent, Angew. Chem. Int. Ed. 2004, 43, 2534-2538.

[31] M. Jbara, S. K. Maity, M. Seenaiah, A. Brik, J. Am. Chem. Soc. 2016, 138, 5069-5075.

[32] S. K. Maity, M. Jbara, G. Mann, G. Kamnesky, A. Brik, Nat. Protoc. 2017, 12, 2293-2322.

[33] M. Jbara, S. Laps, M. Morgan, G. Kamnesky, G. Mann, C. Wolberger, A. Brik, Nat. Commun. 2018, 9, 3154.

[34] N. Naruse, D. Kobayashi, K. Ohkawachi, A. Shigenaga, A. Otaka, J. Org. Chem. 2020, 85, 1425-1433.

[35] H. Katayama, S. Morisue, Tetrahedron 2017, 73, 3541-3547.

[36] P. I. Kitov, D. F. Vinals, S. Ng, K. F. Tjhung, R. Derda, J. Am. Chem. Soc. 2014, 136, 8149-8152.

[37] G.-M. Fang, J.-X. Wang, L. Liu, Angew. Chem. Int. Ed. 2012, 51, 10347-10350.

[38] E. Boll, J.-P. Ebran, H. Drobecq, O. El-Mahdi, L. Raibaut, N. Ollivier, O. Melnyk, Org. Lett. 2015, 17, 130-133.

[39] T. M. Prokop'eva, Y. S. Simanenko, E. A. Karpichev, V. A. Savelova, A. F. Popov, Russ. J. Org. Chem. 2004, 40, 1617-1629.

[40] N. J. Fina, J. O. Edwards, Int. J. Chem. Kinet. 1973, 5, 1-26.

[41] A. F. Trindade, J. W. Bode, Org. Lett. 2016, 18, 4210-4213.

[42] M. Wendeler, L. Grinberg, X. Wang, P. E. Dawson, M. Baca, Bioconjug. Chem. 2014, 25, 93-101.

[43] M. Yanase, K. Nakatsu, C. J. Cardos, Y. Konda, G. Hayashi, A. Okamoto, Chem. Sci. 2019, 10, 5967-5975.

[44] K. Nakatsu, M. Yanase, G. Hayashi, A. Okamoto, Org. Lett. 2020, 22, 4670-4674. 
